\title{
Identification of disease resistance-linked alleles in Vitis vinifera germplasm
}

\author{
Maria Lucia Prazzoli ${ }^{1}$, Silvia Lorenzi ${ }^{1}$, Michele Perazzolli ${ }^{2}$, Silvia Toffolatti ${ }^{3}$, Osvaldo Failla ${ }^{3}$, and Maria Stella \\ Grando ${ }^{1,4, *}$ \\ ${ }^{1}$ Department of Genomics and Biology of Fruit Crops, Research and Innovation Centre, Fondazione Edmund Mach, Via Mach 1 \\ 38010 San Michele all'Adige (Trento), Italy \\ ${ }^{2}$ Department of Sustainable Ecosystems and Bioresources, Research and Innovation Centre, Fondazione Edmund Mach, Via \\ Mach 138010 San Michele all'Adige (Trento), Italy \\ ${ }^{3}$ Department of Agricultural and Environmental Sciences - DiSAA, University of Milano, Via Celoria 220133 Milano, Italy \\ ${ }^{4}$ Center Agriculture Food Environment - C3A, University of Trento, Via Mach 138010 San Michele all'Adige (Trento), Italy
}

\begin{abstract}
Introgression of genetic resistance to fungal diseases from American and Asian Vitis species traditionally pursued in grape breeding programs, although facilitated by molecular tools, has an impact on wine quality that still slows down development of competitive varieties. A contribution to the genetic improvement of grapevines for resistance to pathogens may come from unexplored genetic resources of the Eurasian Vitis vinifera L. In the present study, a hundred grapevine accessions from Georgia, Armenia and Azerbaijan were genotyped with SSR markers linked to QTLs for resistance to downy and powdery mildew, and with 21 SSR markers widely used for genetic diversity and relationship analysis. Looking at population genetic structure, Armenian and Azerbaijani accessions fell within the same cluster and were included among the Central Asian grape varieties of a homogeneous dataset, while Georgian accessions formed a separate group. Pattern of SSR alleles flanking the locus Ren1 and associated with resistance to Erysiphe necator in 'Kishmish vatkana', 'Dzhandzhal kara' and other Central Asian cultivars were found in three varieties from the Azerbaijani population that reached very high scores when assessed for PM resistance.
\end{abstract}

\section{Introduction}

Present day cultivars of the European species Vitis vinifera $\mathrm{L}$. are susceptible to downy (DM) and powdery (PM) mildew, two fungal diseases introduced to Europe from North America during the second half of the XIX century. However, some grapevine populations that have contributed to the origin of modern varieties seem to have evolved specific resistances after the arrival of the pathogens (the oomycete Plasmopara viticola and the ascomycete Erysiphe necator respectively) over a period of sexual reproduction in natural conditions outside cultivated areas. Recent findings also suggest that PM may have existed in the Old World for longer than currently assumed, since several grape species native to Central Asia and China are known to express PM resistance [1].

Even though Russian grapevine breeders had already used $V$. vinifera germplasm of Central Asian origin as a source of resistance to PM [2], only the identification of the Ren1 locus of resistance to Erysiphe necator in the 'Kishmish vatkana' grapevine cultivar [3] has recently brought attention to the Eurasian genetic resources of $V$. vinifera for current resistance breeding programs.

Low levels of susceptibility to diseases in field and controlled conditions were reported for several grapevine accessions coming from South Caucasus, which also show desirable fruit traits and a certain degree of tolerance to environmental stresses $[4,5]$. To investigate the genetic basis of the most interesting phenotypes among this germplasm, several accessions were screened in the present study with molecular markers linked to Ren1 locus and to several genetic loci of partial resistance to DM (Rpv) and PM (Run, Ren) formerly identified in American and Asian Vitis species.

\section{Materials and methods}

A collection of a hundred accessions of $V$. vinifera ssp. sativa and ssp. sylvestris from Georgia, Armenia and Azerbaijan established at DiSAA (University of Milan, ITA 426) within the Cost Action FA1003 [6] was genotyped at 21 neutral SSR loci, including the standard set of microsatellites widely used for grapevine genetic identification. The list of molecular markers and

\footnotetext{
Corresponding author: stella.grando@unitn.it
} 
conditions of analysis were previously reported [7]. Population genetic structure and main diversity statistics were investigated with STRUCTURE v2.3.4 and GenAlex v6.502 software, including homologous genetic data of the grapevine germplasm from Central Asia and Israel as described by [8,9].

Non-redundant grapevine genotypes from Georgia, Armenia and Azerbaijan were further analyzed at 26 marker loci (24 SSR, 1 CAPS and 1 SCAR) linked to several QTLs for DM and/or PM resistance according to published protocols, as summarized in Table 1. The QTLs Rpv1/Run1, Rpv3, Rpv10, Rpv12 and Ren3 were identified for resistance to $P$. viticola (Rpv) and $E$. necator (Run, Ren) in North American and Asian Vitis species. Molecular markers linked to the Ren1 genomic region were detected in the Central Asian grapevine cultivars 'Kishmish vatkana' and 'Dzhandal kara' (Table 1).

\section{Results and discussion}

Based on allelic profiles at neutral SSR loci, the collection of grapevines from South Caucasus was finally composed of 17 different varieties of Armenian origin, 35 varieties of Azerbaijani origin, and 7 putative $V$. vinifera ssp. sylvestris individuals and 18 varieties from Georgia.

When compared with other grapevine germplasm included in the genetic dataset, Georgian and Israeli genetic resources showed the highest allelic richness, both populations also containing a large proportion of private alleles (Figure 1). Analysis with STRUCTURE indicated $\mathrm{K}=3$ and $\mathrm{K}=5$ as the most likely number of clusters in the genetic structure of the germplasm. At $\mathrm{K}=3$ all Armenian and Azerbaijani accessions fell within the same cluster with a percentage of assignment higher than $80 \%$, and were included among the accessions of Tajikistan, Uzbekistan and Kyrgyzstan regions of Central Asia described by [8]. Georgian and Israeli germplasm formed two separate groups (Figure 2). At $\mathrm{K}=5$ Georgian accessions revealed two clusters roughly corresponding to wild and cultivated genotypes while the cluster of Armenian and Azerbaijani accessions was separated from the group of Central Asia (data not shown).

Within the population from Azerbaijan, four unique multilocus genotypes corresponding to accessions 12AZ3, 12AZ16, 12AZ23 and 12AZ41 showed identical marker profile to accessions HOP L04-19 Rish Baba, 2271Mtp2 Baïan chirei, 2842Mtp1 Ag Kiourdach p.e. and DVIT0310 Barmak Isium included in the large germplasm evaluated at Ren1-linked markers by [1]. The last study provided evidence that PM resistance was present in other cultivated $V$. vinifera of Central Asia besides 'Kishmish vatkana' and 'Dzhandzhal kara' and also in individuals of $V$. vinifera ssp. sylvestris, suggesting that additional germplasm may share a Ren1like local haplotype.

Disease evaluation under natural and controlled conditions has indicated phenotypes of reduced susceptibility to DM and/or PM within the South
Caucasus germplasm included in our survey, with Armenian and Azerbaijani accessions worthy of note for resistance to $\mathrm{PM}$ and accessions from Georgia less susceptible to DM $[4,5]$.

Patterns of SSR alleles of the expected size in both regions flanking the locus Ren1 were actually found in three varieties of the Azerbaijani population (Table 2) that reached very high scores when assessed for PM resistance on leaves (OIV descriptor code 455). In addition, another 15 accessions scored from 7 to 9, including three putative $V$. vinifera ssp. sylvestris individuals, deserving further attention, as they showed only some of the Ren1-linked alleles compared to the 'Kishmish vatkana' and 'Dzhandzhal kara' haplotype (a few examples are shown in Table 2).

Conversely, no allelic sizes linked to Run1 and Ren3 resistance loci were detected in the South Caucasus populations. Similarly, no accessions showed DM resistance-linked alleles on both sides of the targeted Rpv QTLs, which would have suggested a hybrid origin of the accessions, though not supported by preliminary phylogenetic analyses. Nevertheless, some SSR alleles associated with resistance at Rpv1 and Rpv3 loci (in $V$. rotundifolia and $V$. rupestris, respectively) and with resistance at Rpv10 and Rpv12 loci in $V$. amurensis were detected in the germplasm on one side or the other of the QTLs (Table 3).

Table 1. DM and PM resistance markers applied in this study.

\begin{tabular}{|c|c|c|c|}
\hline Locus & $\begin{array}{l}\text { Associated } \\
\text { marker }\end{array}$ & $\begin{array}{l}\text { Allele size } \\
\text { linked to } \\
\text { resistance } \\
\text { (bp) }\end{array}$ & Ref. \\
\hline \multirow{5}{*}{ Rpv1/Run1 } & VMC1g3.2 & 118 & \multirow{5}{*}[10,11,12]{} \\
\hline & VVIM11 & 292 & \\
\hline & VMC8g9 & 156 & \\
\hline & VMC4f3.1 & 188 & \\
\hline & CAPS GLP1-12 & 650,200 & \\
\hline \multirow{3}{*}{ Rpv3 } & UDV305 & 299 & \multirow{3}{*}[13,14]{} \\
\hline & VMC7f2 & 210 & \\
\hline & UDV737 & 296 & \\
\hline \multirow{6}{*}{ Rpv10 } & GF09-44 & 230 & \multirow{6}{*}{ [15] } \\
\hline & GF09-46 & 410 & \\
\hline & GF09-47 & 296 & \\
\hline & GF09-48 & 355 & \\
\hline & GF09-52 & 390 & \\
\hline & GF09-55 & 249 & \\
\hline \multirow{5}{*}{ Rpv12 } & UDV343 & 161 & \multirow{5}{*}{ [16] } \\
\hline & UDV345 & 220 & \\
\hline & UDV350 & 308 & \\
\hline & UDV360 & 208 & \\
\hline & UDV370 & 198 & \\
\hline \multirow{6}{*}{ Ren1 } & UDV124 & 214 & \multirow{6}{*}[3,17]{} \\
\hline & SC8-0071-014 & 142 & \\
\hline & SC47-18 & 248 & \\
\hline & VMC9h4 & 282 & \\
\hline & VMC4e10 & 258 & \\
\hline & UDV20 & 158 & \\
\hline Ren3 & ScORA7-760 & 760 & [18] \\
\hline
\end{tabular}




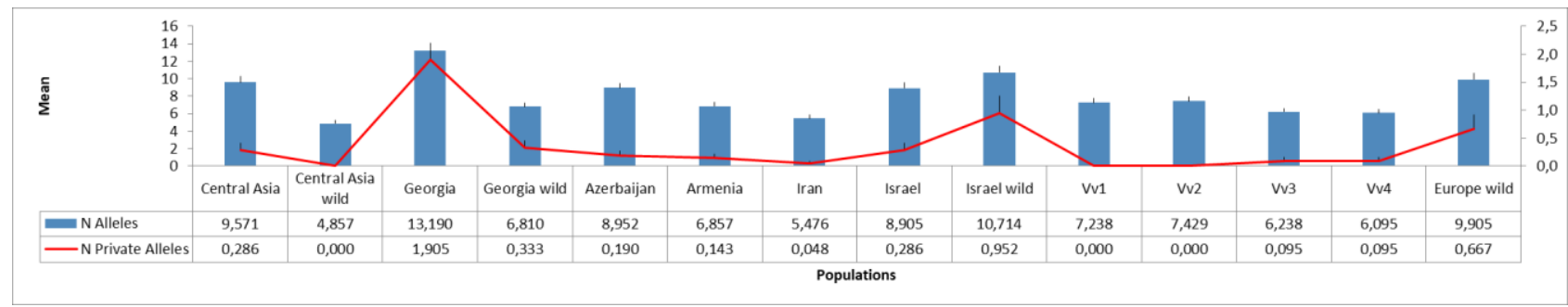

Fig. 1. Mean number of alleles per locus and private alleles for each population of the South Caucasus and the homologous dataset (Vv1, Vv2, Vv3 e Vv4 refer to ancestral subpopulations of cultivated grapevine detected by [7] and consistent with Negrul's grouping).

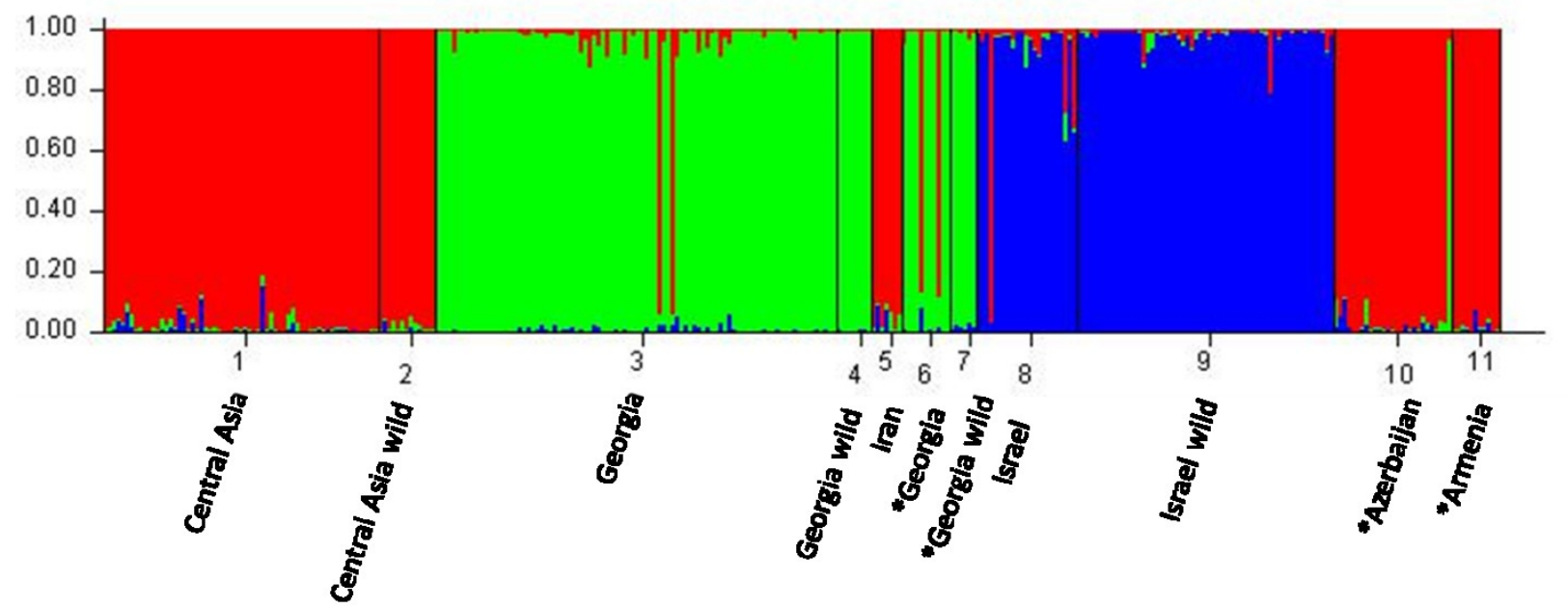

Fig. 2. Genetic population structure for $K=3$. Each unique $S S R$ genotype is shown as a vertical line portioned into segments representing the estimated coefficients of membership proportion in the three genetic clusters inferred with STRUCTURE. Regional populations also investigated at resistance loci (examples in Table 2 and Table 3 ) are indicated by an asterisk $(*)$.

Table 2. Allele data of a subset of grapevine cultivars for SSR markers flanking the Ren1 locus.

Allele sizes associated with PM resistance in 'Kishmish vatkana' and 'Dzhandzhal kara' cultivars are in bold.

Degree of resistance to PM is reported according to the OIV-455 scoring ( $5=$ medium, $9=$ very high).

\begin{tabular}{|c|c|c|c|c|c|c|c|c|c|c|c|c|c|c|c|}
\hline \multirow{2}{*}{\multicolumn{2}{|c|}{ Accession name }} & \multirow{2}{*}{ Origin } & \multirow{2}{*}{ OIV 455} & \multicolumn{12}{|c|}{ Ren1 } \\
\hline & & & & \multicolumn{2}{|c|}{ UDV124 } & \multicolumn{2}{|c|}{ SC8-0071-014 } & \multicolumn{2}{|c|}{ SC47-18 } & \multicolumn{2}{|c|}{ VMC9h4 } & \multicolumn{2}{|c|}{ VMC4e10 } & \multicolumn{2}{|c|}{ UDV20 } \\
\hline & Kishmish vatkana & control & 9 & 214 & - & 142 & 160 & 232 & 248 & 258 & 282 & 236 & 258 & 142 & 158 \\
\hline & Dzhandal kara & control & 9 & 214 & 218 & 142 & 176 & 228 & 248 & 276 & 282 & 254 & 258 & 142 & 158 \\
\hline $12 \mathrm{AZ} 28$ & Khyndogny N. & Azerbaijan & 8,9 & 194 & 214 & 142 & 172 & 216 & 242 & 270 & 274 & 248 & 252 & 142 & 158 \\
\hline $12 \mathrm{AZ} 32$ & Madrasa N. & Azerbaijan & 9 & 194 & 214 & 142 & 172 & 216 & 240 & 270 & 274 & 252 & 258 & 142 & 158 \\
\hline $12 \mathrm{AZ} 27$ & Huseiny & Azerbaijan & 9 & 184 & 214 & 160 & 162 & 240 & 248 & 274 & 276 & 252 & 254 & 142 & 158 \\
\hline $12 \mathrm{AZ} 12$ & Alykhanly Garagyoz N. & Azerbaijan & 8,5 & 210 & 218 & 166 & 170 & 228 & 248 & 276 & 282 & 254 & 258 & 142 & 144 \\
\hline $12 \mathrm{AZ} 40$ & Surmeyi N. & Azerbaijan & 7,9 & 210 & 218 & 166 & 170 & 226 & 248 & 276 & 282 & 254 & 258 & 142 & 144 \\
\hline $12 \mathrm{AZ} 30$ & Khart-Kart & Azerbaijan & 9 & 190 & 194 & 160 & 170 & 240 & 248 & 274 & 284 & - & - & 158 & 160 \\
\hline $12 \mathrm{AZC}$ & $\mathrm{N} 2$ & Azerbaijan & 9 & 210 & 218 & 172 & 202 & 236 & 248 & 286 & 286 & - & - & 142 & 158 \\
\hline AR 11 & Kakhet & Armenia & 9 & 186 & 214 & 142 & 200 & 236 & 242 & 284 & 298 & - & - & 132 & 142 \\
\hline
\end{tabular}


Table 3. Allele data of a subset of Georgian accessions for SSR markers flanking three QTLs for resistance to DM. Disease resistance-linked alleles identified in Vitis spp. are in bold.

\begin{tabular}{|c|c|c|c|c|c|c|c|c|c|c|c|c|c|c|}
\hline \multirow{2}{*}{\multicolumn{2}{|c|}{ Accession name }} & \multirow{3}{*}{$\begin{array}{c}\text { Origin } \\
\text { control }\end{array}$} & \multicolumn{4}{|c|}{ Rpv3 } & \multicolumn{4}{|c|}{ Rpv12 } & \multicolumn{4}{|c|}{ Rpv10 } \\
\hline & & & \multicolumn{2}{|c|}{ UDV737 } & \multicolumn{2}{|c|}{ VMC7f2 } & \multicolumn{2}{|c|}{ UDV370 } & \multicolumn{2}{|c|}{ UDV350 } & \multicolumn{2}{|c|}{ GF09_46 } & \multicolumn{2}{|c|}{ GF09_47 } \\
\hline & V. amurensis & & - & - & - & - & 194 & 198 & 308 & 308 & 410 & 420 & 294 & 296 \\
\hline & $V$. rupestris & control & 280 & 296 & 200 & 210 & - & - & - & - & - & - & - & - \\
\hline EST11f & Zhghia Sagviano & Georgia & - & - & 200 & 204 & 192 & 194 & 300 & 300 & - & - & 292 & 296 \\
\hline EST2-8A & Kapistoni Tsitsiliani & Georgia & - & - & 202 & 204 & 190 & 192 & - & - & 410 & 420 & - & - \\
\hline EST32-2 & Borchalo & Georgia & 296 & 296 & 200 & 200 & 190 & 190 & 306 & 308 & 418 & 418 & 294 & 294 \\
\hline $\mathrm{g} 41$ & Chitistvala Acharul & Georgia & 292 & 296 & 200 & 200 & 190 & 192 & 308 & 322 & 406 & 406 & 288 & 292 \\
\hline ESTSK & Saperavi Khashmis & Georgia & 284 & 284 & 200 & 204 & 190 & 198 & - & - & 410 & 420 & 294 & 294 \\
\hline EST.WF10 & wild & Georgia & 296 & 296 & 200 & 200 & 192 & 198 & 300 & 322 & 418 & 418 & 294 & 294 \\
\hline EST.WF110/298 & wild & Georgia & - & - & 200 & 204 & 190 & 192 & 300 & 300 & 416 & 416 & 292 & 296 \\
\hline L22 & Mgalobshivili & Georgia & 294 & 294 & 206 & 206 & 188 & 196 & 306 & 308 & 402 & 418 & 290 & 294 \\
\hline
\end{tabular}

\section{Conclusions}

In this preliminary investigation, we exploited available genetic information on fungal disease resistance to characterize a grapevine germplasm collection from South Caucasus [19]. We showed that powdery mildew resistance phenotypes of three cultivated varieties from Azerbaijan not included in previous surveys can be attributed to Ren1-like genotypes. This finding is consistent with a weak genetic structure revealed by neutral SSR markers among regional accessions of Armenian, Azerbaijani and Central Asian origin. Using a marker assisted selection approach, those accessions which may also bring other favorable traits, can directly contribute to resistance gene pyramiding and diversification of plant defense mechanisms by intraspecific cross breeding, perhaps with reduced linkage drag effect on the quality of final wines.

We want to thank the FEM and DiSAA collection staffs for germplasm maintenance. This work was carried out in the framework of COST Action FA1003 "East-West Collaboration for Grapevine Diversity Exploration and Mobilization of Adaptive Traits for Breeding" with the financial support of FEM to doctoral student M.L. Prazzoli.

\section{References}

1. S. Riaz, J-M. Boursiquot, G.S. Dangl, T. Lacombe, V. Laucou, A.C. Tenscher, M.A. Walker, BMC Plant Biology 13, 149 (2013)

2. I.M. Filippenko L.T, Stin, Bull Nauchn Inform CGL IV Michurina 25, 57-58 (1977)

3. S. Hoffmann, G. Di Gaspero, L. Kovács, S. Howard, E. Kiss, Z. Galbács, R. Testolin, P. Kozma, Theor Appl Genet 116, 427-438 (2008)

4. O. Failla, P.A. Bianco, L. Brancadoro, S. Toffolatti, G. Maddalena, F. Quagliano, L. Rustioni, G. De Lorenzis, S. Fiori, G.S. Di Lorenzo, A. Scienza, D. Maghradze, Frutticoltura 1/2 (2016)

5. S.L. Toffolatti, G. Maddalena, D. Salomoni, D. Maghradze, P.A. Bianco, O. Failla, Vitis 55, 121-128 (2016)
6. O. Failla, Vitis 54 (Special issue) 1-4 (2015)

7. F. Emanuelli, S. Lorenzi, L. Grzeskowiak, V. Catalano, M. Stefanini, M. Troggio, S. Myles, J.M. MartinezZapater, E. Zyprian, F.M. Moreira, M.S. Grando, BMC Plant Biology 13, 39 (2013)

8. A. Marrano, L. Grzeskowiak, P. Moreno Sanz, S. Lorenzi, M.L. Prazzoli, A. Arzumanov, M. Amanova, O. Failla, D. Maghradze, M.S. Grando, Vitis 54 (Special issue) 233237 (2015)

9. E. Drori, O. Rahimi, A. Marrano, Y. Henig, H. Brauner, M. Slmon-Divon, Y. Netzer, M.L. Prazzoli, M.L., M. Stanevsky, O. Failla, E. Weiss E, M.S. Grando, Sci. Rep. 7, 44463 (2017)

10. C.L. Barker, T. Donald, J. Pauquet, M.B. Ratnaparkhe, A. Bouquet, A.F. Adam-Blondon, M.R. Thomas, I. Dry, Theor Appl Genet 111, 370-377 (2005)

11. D. Debreceni, A. K. Lencsés, A. Szőke, A. Veres, S. Hoffmann, P. Kozma, L.G. Kovacs, L. Heszky, E. Kiss, Sci Hort 126, 448-453 (2010)

12. S. Molnar, Z. Galbacs, G. Hasasz, S. Hoffmann, E. Kiss, P. Kozma, A. Veres, Z. Galli, A. Szöke, L. Heszky, Vitis 46, 212-213 (2007)

13. D. Bellin, E. Peressotti, D. Merdinoglu, S. WiedemannMerdinoglu, A.F. Adam- Blondon, G. Cipriani, M. Morgante, R. Testolin, G. Di Gaspero, Theor Appl Genet 120, 163-176 (2009)

14. G. Di Gaspero, D. Copetti, C. Coleman, S. D. Castellarin, R. Eibach, P. Kozma, T. Lacombe, G. Gambetta, A. Zvyagin, P. Cindrić, L. Kovács, M. Morgante, R. Testolin R, Theor Appl Genet 124, 277-286 (2012)

15. F. Schwander, R. Eibach, I. Fechter, L. Hausmann, E. Zyprian, R. Töpfer, Theor Appl Genet 124, 163-176 (2011)

16. S. Venuti, D. Copetti, S. Foria, L. Falginella, S. Hoffmann, D. Bellin, P. Cindrić, P. Kozma, S. Scalabrin, M. Morgante, R. Testolin, G. Di Gaspero, PLOS ONE 8, 4, (2013)

17. C. Coleman, D. Copetti, G. Cipriani, S. Hofmann, P. Kozma, L. Kovacs, M. Morgante, R. Testolin, G. Di Gaspero, BMC Genet 10, 89 (2009)

18. L.J. Welter, N. Göktürk-Baydar, M. Akkurt, E. Maul, R. Eibach, R. Töpfer, E. Zyprian, Mol Breed 20, 359-374 (2007)

19. M.L Prazzoli, Doctoral Thesis, University of Milano, Agriculture, Environment and Bioenergy, XXIX cycle a.y. (2016/2017) 